\title{
Ocular Manifestations of COVID-19: A Systematic Review and Meta-analysis
}

\author{
Naser Nasiri ${ }^{1}$, MS; Hamid Sharifi ${ }^{1}$, PhD; Azam Bazrafshan ${ }^{2}$, MS; Atefeh Noori ${ }^{3}$, MS \\ Mohammad Karamouzian ${ }^{1,4}$, MS; Ali Sharifi ${ }^{5}$, MD \\ ${ }^{1}$ HIV/STI Surveillance Research Center, and WHO Collaborating Center for HIV Surveillance, Institute for Futures Studies in \\ Health, Kerman University of Medical Sciences, Kerman, Iran \\ ${ }^{2}$ Neuroscience Research Center, Institute of Neuropharmacology, Kerman University of Medical Sciences, Kerman, Iran \\ ${ }^{3}$ Department of Health Research Methods, Evidence, and Impact, McMaster University, Hamilton, ON, Canada \\ ${ }^{4}$ School of Population and Public Health, Faculty of Medicine, University of British Columbia, Vancouver, BC, Canada \\ ${ }^{5}$ Department of Ophthalmology, Shafa Hospital, Afzalipour School of Medicine, Kerman University of Medical Sciences, \\ Kerman, Iran
}

ORCID:

Naser Nasiri: https://orcid.org/0000-0002-1505-0866

Ali Sharifi: https://orcid.org/0000-0003-0713-088X

\section{Abstract}

Several studies have reported the characteristics of Coronavirus disease 2019 (COVID-19), yet there is a gap in our understanding of the ocular manifestations of COVID-19. In this systematic review and meta-analysis, we investigated the prevalence of ocular manifestations in COVID-19 patients. We searched Pubmed, Embase, Scopus, Web of Science, and medRxiv from December 1, 2019 to August 11, 2020. Two independent reviewers screened the articles, abstracted the data, and assessed the quality of included studies in duplicate. Thirty-eight studies were eligible after screening of 895 unique articles, with a total of 8,219 COVID-19 patients (55.3\% female; $n=3,486$ out of 6,308 patients). Using data extracted from cross-sectional studies, we performed randomeffects meta-analyses to estimate the pooled prevalence of ocular symptoms along with $95 \%$ confidence interval (Cl). The prevalence of ocular manifestations was estimated to be $11.03 \%$ (95\% $\mathrm{Cl}$ : 5.71-17.72). In the studies that reported the details of observed ocular symptoms, the most common ocular manifestations were dry eye or foreign body sensation $(n=138,16 \%)$, redness $(n$ $=114,13.3 \%)$, tearing $(n=111,12.8 \%)$, itching $(n=109,12.6 \%)$, eye pain $(n=83,9.6 \%)$ and discharge ( $n=76,8.8 \%$ ). Moreover, conjunctivitis had the highest rate among reported ocular diseases in COVID-19 patients (79 out of $89,88.8 \%$ ). The results suggest that approximately one out of ten COVID-19 patients show at least one ocular symptom. Attention to ocular manifestations, especially conjunctivitis, can increase the sensitivity of COVID-19 detection among patients.

Keywords: Conjunctivitis; COVID-19; Meta-analysis; Ocular Manifestations; Systematic Review

J Ophthalmic Vis Res 2021; 16 (1): 103-112

\section{Correspondence to:}

Ali Sharifi, MD. Department of Ophthalmology, Shafa Hospital, Afzalipour School of Medicine, Kerman University of Medical Sciences, Kerman, Iran.

E-mail: a_sharifi@kmu.ac.ir; sharifialim2@gmail.com

Received: 01-10-2020 Accepted: 28-12-2020

\section{Access this article online}

Website:

https://knepublishing.com/index.php/JOVR

DOI:

10.18502/jovr.v16i1.8256

\section{INTRODUCTION}

Severe acute respiratory syndrome coronavirus 2 (SARS-CoV-2) was initially detected in late

This is an open access journal, and articles are distributed under the terms of the Creative Commons Attribution-NonCommercial-ShareAlike 4.0 License, which allows others to remix, tweak, and build upon the work non-commercially, as long as appropriate credit is given and the new creations are licensed under the identical terms.

How to cite this article: Nasiri $N$, Sharifi $H$, Bazrafshan $A$, Noori $A$, Karamouzian M, Sharifi A. Ocular Manifestations of COVID-19: A Systematic

Review and Meta-analysis. J Ophthalmic Vis Res 2021;16:103-112. 
2019 in Wuhan, China, ${ }^{[1]}$ and Coronavirus disease 2019 (COVID-19) swiftly spread across the globe, and was declared a pandemic on March 11, $2020 .^{[2]}$ By August 14, 2020, 21,092,096 people were infected with SARS-CoV-2, 757,727 of whom passed away due to COVID-19 or its adverse health consequences. $^{[3]}$

COVID-19 may pose challenges in clinical diagnosis because there is no pathognomonic symptom to detect the disease. Several clinical symptoms have been frequently reported among COVID-19 patients including but not limited to cough, fever, fatigue, sore throat, nasal obstruction, shortness of breath, headache, sputum production, and hemoptysis. ${ }^{[4]}$ Moreover, while some patients show a wider range of gastrointestinal symptoms such as diarrhea, abdominal pain, low appetite, and vomit, ${ }^{[5]}$ others have shown renal and ocular symptoms. ${ }^{[6]}$

Most clinical research about SARS-CoV-2 have focused on respiratory manifestations; however, a growing body of evidence has raised concerns about the ocular complications caused by SARSCoV-2. ${ }^{[7]}$ The reported ocular manifestations of the infection vary greatly and include dry eye, foreign body sensation, itching, blurring of vision, conjunctivitis, chemosis, and photophobia. ${ }^{[8]}$ Some studies have even reported conjunctivitis as an early sign for COVID-19 diagnosis. ${ }^{[9]}$ Knowing the prevalence and type of ocular manifestations of COVID-19 can help physicians diagnose the infection better and sooner in the course of the disease. Therefore, we aimed to summarize the relevant published literature on the ocular manifestations of the COVID-19 patients.

\section{METHODS}

We completed our systematic review in accordance with the preferred reporting items for systematic reviews and meta-analyses (PRISMA) guideline (See Supplementary file S1 for PRISMA checklist). ${ }^{[10]}$

For this systematic review and meta-analysis, we searched Pubmed, Embase, Scopus, Web of Science, and medRxiv preprint server from December 1, 2019 to August 11, 2020 for studies published in English (See Supplementary file S2 for a sample search strategy). We also searched the reference lists of related systematic reviews for potentially eligible studies.

\section{Inclusion Criteria and Study Selection}

We included empirical observational studies including cohort, case-control, cross-sectional, case-reports, or case-series that reported about ocular manifestations in COVID-19 patients. We excluded editorials, commentaries, letters to editors, and reviews. Two reviewers ( $\mathrm{NN}$ and $\mathrm{HSH}$ ) independently, and in duplicate, screened the titles and abstracts of identified citations, and assessed the full-text of potentially eligible studies for inclusion in the data synthesis. The reviewers resolved the disagreements on the process of study selection through feedback and discussion with the senior author (ASH).

\section{Data Collection}

Two authors (NN and $\mathrm{AB}$ ) independently, and in duplicate, extracted data from each eligible study, including study characteristics (e.g., first author, publication date, study type, location, and total sample size) and patients' information (e.g., age, sex, and ocular manifestations such as conjunctival hyperemia, clear secretions, conjunctivitis, follicles, petechia, and chemosis).

\section{Quality Assessment of the Evidence}

Two independent reviewers evaluated the quality of included studies duplicate using the Joanna Briggs Institute critical appraisal tool. ${ }^{[11]}$ The criteria suggested by Joanna Briggs to assess quality include eight items for case-report studies, nine items for cross-sectional studies, and ten items for case-series. Reviewers resolved the disagreements by adjudication or feedback from the senior author.

\section{Statistical Analysis}

Data were presented using descriptive statistics (i.e., mean, median, and standard deviation [SD] for continuous variables and frequency and percentage for categorical variables). To assess the proportion of patients with a particular manifestation, we calculated the sum of the patients with a particular manifestation in different papers and divided them to the number of included patients. To account for the different study designs included in the study, we only 
considered cross-sectional studies in our metaanalysis. Using random-effects meta-analysis, we calculated the pooled estimated prevalence and $95 \%$ confidence interval $(95 \% \mathrm{Cl})$ of ocular manifestations, using metaprop command in Stata version 14.2. We also assessed the heterogeneity among the included studies using $\mathrm{I}^{2}$ and the $Q$-statistic. A value of $\geq 50 \%$ of $\mathrm{I}^{2}$ and a $P$ value of $<0.1$ for the $Q$-statistic was perceived as considerable heterogeneity. We then ran a meta-regression to assess the potential sources of heterogeneity. The following variables were included in the meta-regression: Method of COVID-19 diagnosis (polymerase chain reaction [PCR] or computed tomography scan [CT scan] vs clinical signs), the quality of studies (quality score $<4$ vs quality score $\geq 4$ ), the mean age of patients (age $\leq 45$ years vs age $>45$ years), the method of examination by ophthalmologist (standard ophthalmic exam vs non-standard ophthalmic exam), and the recruited sample size (sample size $>500$ vs sample size $\leq 500$ ). Based on the reported information in the papers, we also aimed to assess whether the reported ocular manifestations preceded or followed the presence of systemic symptoms. To do so, we calculated the lag between ocular manifestation and systemic disease as well as the lag between systemic disease and ocular manifestation. All statistical analyses were performed in Stata version 14.2 and all comparisons were two-tailed, with a threshold $P$-value of 0.05 .

\section{RESULTS}

Out of the 895 unique publications that were assessed, 38 studies $^{[12-49]}$ were included in this review (Figure 1). Overall, 13 studies were case reports, ${ }^{[37-49]}$ six were case-series study, ${ }^{[13,15,18,25,28,36]}$ and the remaining 19 studies were cross-sectional. ${ }^{[12,14,16,17,19-24,26,27,29-35]}$ Twenty-four studies reported aggregate-leve ${ }^{[12-35]}$ and fourteen ${ }^{[36-49]}$ reported individual-level information about ocular manifestations. Out of the 38 studies, 1 study ${ }^{[16]}$ was conducted among healthcare providers (see Supplementary file S3 for type of study, sex, mean age, and main ocular manifestations; Supplementary file S4 for location, publication data, patient population, and chronic disease). Moreover, out of the 38 included studies, 32 (3,719 out of 8,219 patients) were among inpatients, four among outpatients $(2,353$ out of
8,219 patients), and two included outpatient and inpatient individuals, simultaneously $(2,147$ out of 8,129 patients).

Demographic and clinical characteristics of COVID-19 patients included in the reviewed studies are presented in Table 1. A total of 8,219 patients with COVID-19 were enrolled in the included studies. Across all COVID-19 studies, 6,308 reported sex distribution, 1,532 reported other comorbidities with COVID-19, and 1,021 were at the individual level and reported ocular symptoms and signs. The number of enrolled patients in the included studies ranged from 1 to 1,452 , most patients were female ( $n=3,486$ out of 6,308 patients, $55.3 \%$ ), and the mean age of the participants ranged between 7 and 65.8 years. The diagnosis of SARS-CoV-2 was confirmed in 4,039 (49.1\%) and 4,180 (50.9) patients using clinical signs and CT scans. The most detected comorbidities in patients were hypertension (593 out of 1,532), diabetes mellitus (294 out of 1,532), respiratory diseases (219 out of 1,532), and cardiovascular and cerebrovascular diseases (188 out of 1,532).

\section{Quality Assessment of Included Studies}

Joanna Briggs Institute's critical appraisal scores ranged from 2 to 6 for case reports (out of 8 possible points), and 0 to 5 for prevalence (crosssectional) studies (out of 9 possible points), and 3 to 7 (out of 10 possible points) for single case-series included in the review. Quality assessment tools were different based on study design; therefore, scores could not be directly compared (See Supplementary file S5).

\section{The Pooled Prevalence of Ocular Manifestations}

We included 19 cross-sectional studies corresponding to 7,300 individuals for metaanalysis of ocular manifestations among patients with COVID-19. The pooled prevalence of all ocular manifestations among COVID -19 patients was $11.03 \%$ (95\% Cl: 5.71 to 17.72) (Figure 2), The most prevalent ocular manifestations were dry eye or foreign body sensation ( $n=138,16.0 \%$ ), redness ( $n=114,13.3 \%)$, tearing ( $n=111,12.8 \%$ ), itching ( $n=109,12.6 \%$ ), eye pain ( $n=83,9.6 \%$ ), and discharge ( $n=76,8.8 \%$ ). The most prevalent ocular disease was conjunctivitis ( $n=79,88.8 \%$ ). 


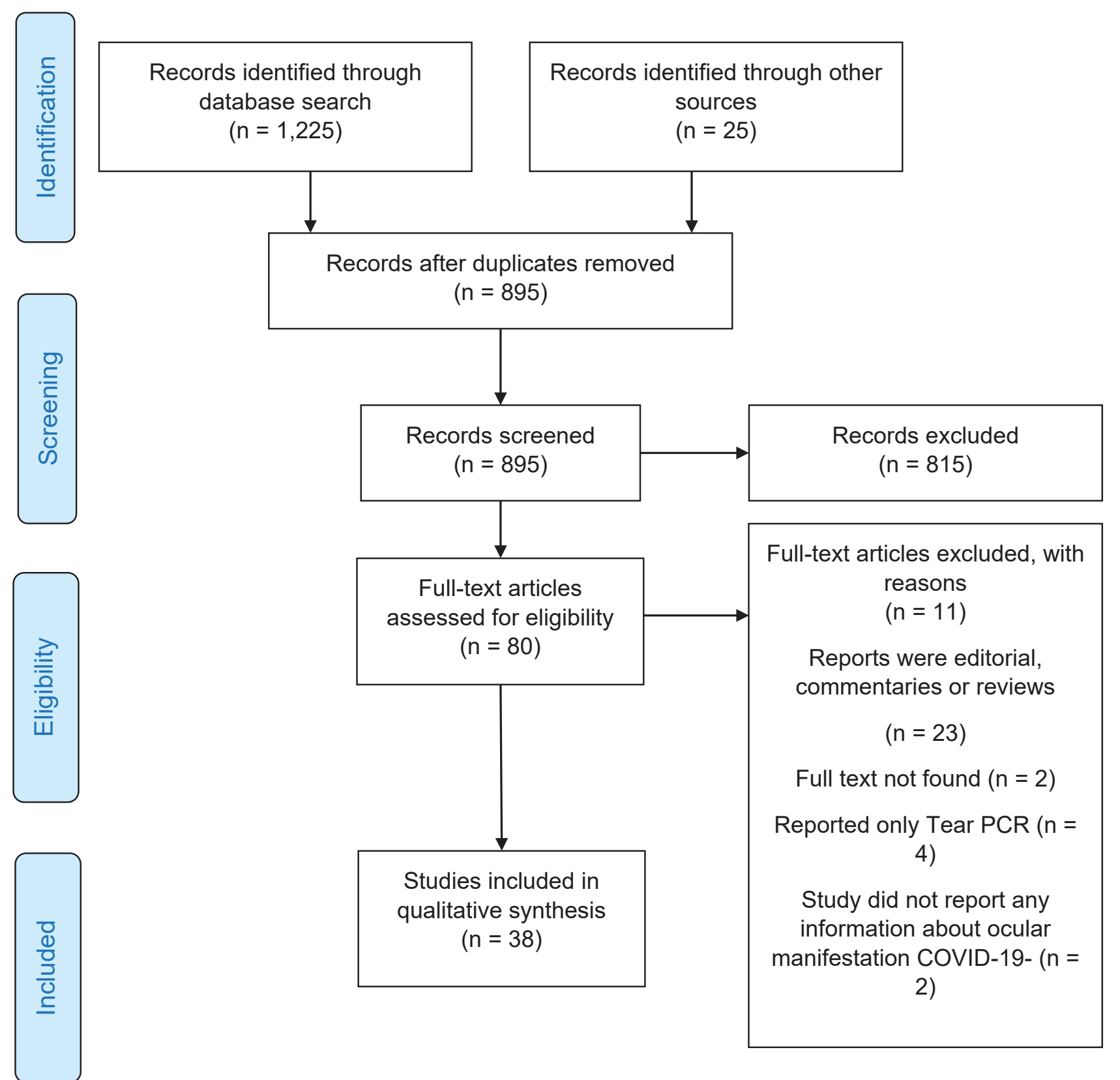

Figure 1. Flowchart of studies included in the systematic review of COVID-19 ocular manifestation

Other rare conditions such as keratitis ( $n=2,2.2 \%)$, episcleritis ( $n=2,2.2 \%$ ), keratoconjunctivitis ( $n=$ $2,2.2 \%$ ), hordeolum ( $n=2,2.2 \%$ ), pingueculitis $(n=1,1.1 \%)$, posterior ischemic optic neuropathy ( $n=1,1.1 \%)$ were also reported (Table 2$)$. No significant source of heterogeneity from the included variables in the meta-regression was detected (Table 3).

Five studies reported the lag between ocular manifestation and systemic disease; however, nine studies reported the lag between systemic disease and ocular manifestation. Weighted mean between onset ocular manifestations and systemic disease was 0.04 days (range, 1 to 3 days). However, weighted mean between systemic disease and ocular manifestation was 1.5 days (range, 2 to 21 days).

\section{DISCUSSION}

This systematic review and meta-analysis included 38 studies with a total of 8,219 COVID-19 patients. 


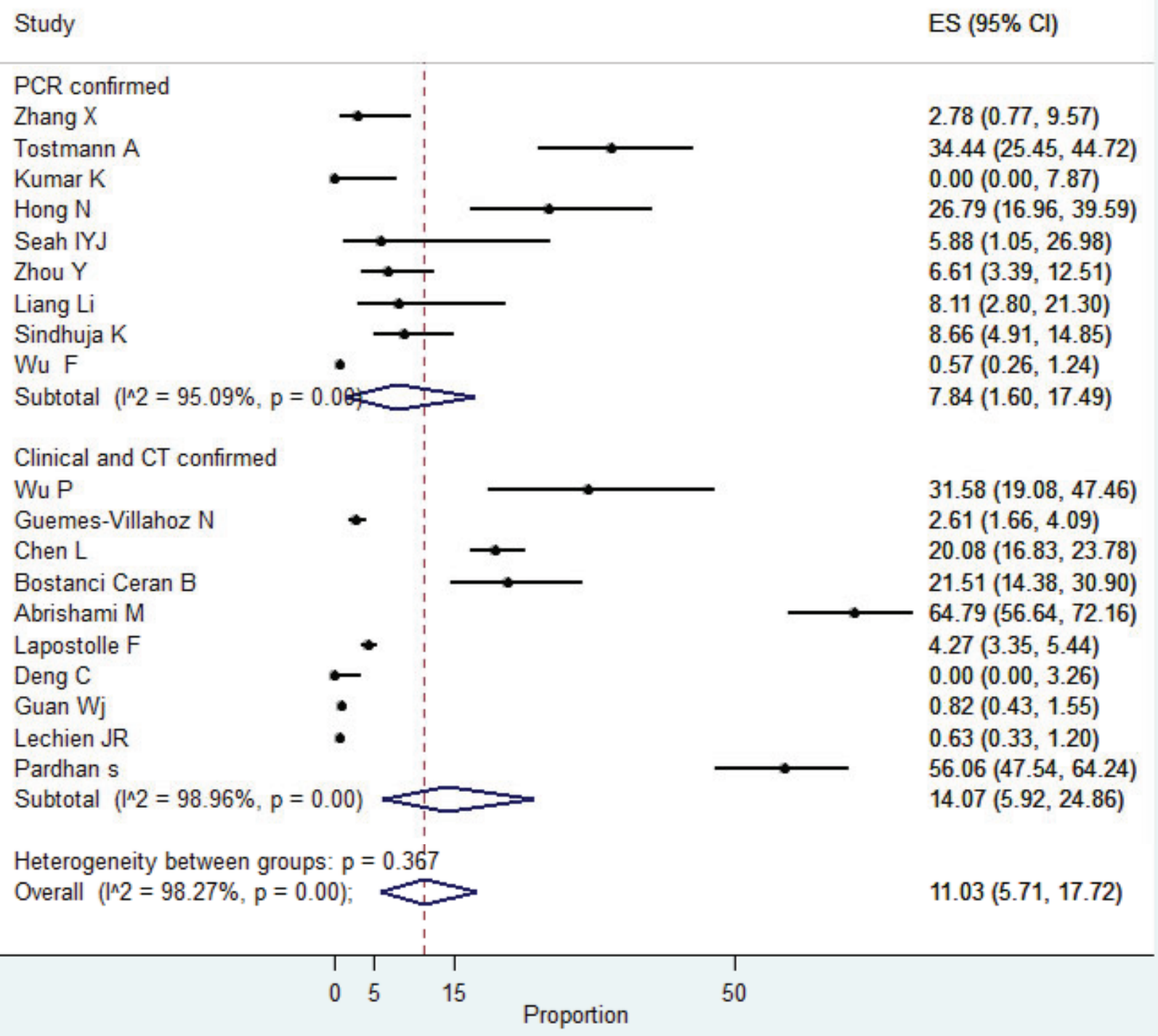

Figure 2. Pooled prevalence of ocular manifestation among patients with COVID-19

Based on the existing evidence, we found the pooled prevalence of all ocular symptoms to be $11.03 \%$ (95\% Cl: 5.71 to 17.72) among COVID19 patients. Dry eye or foreign body sensation was the most common reported ocular symptoms (16.0\%), followed by redness (13.3\%) and tearing (12.8\%). The most prevalent ocular disease was conjunctivitis (88.8\%).

This study showed that approximately one out of ten COVID-19 patients included in this study showed at least one ocular manifestations. Although these manifestations may not be frequent, they should not be overlooked by physicians and ophthalmologists. ${ }^{[50]}$ These findings are comparable with the findings of previous studies on COVID-19 or other coronaviruses. For example, Vabret et al in a study in a French hospital, from November 2002 to April 2003, reported that ocular manifestations were $16.7 \%$ ( 3 out of 18 ) in patients diagnosed with human coronavirus NL63. ${ }^{[51]}$ Moreover, Ulhaq et $a$ l in a systematic review study up to April 4, 2020 reported that ocular manifestations in COVID-19 patients were 5.5\%. ${ }^{[52]}$ The reason for ocular manifestations among patients diagnosed with COVID-19 and other coronaviruses could be related to the presence of ACE2 receptor, the cell receptor for coronaviruses and SARS-CoV-2, in 
Table 1. Demographic and clinical characteristics of COVID-19 infection included in the reviewed studies

Characteristics

N (\%)

Diagnostic approach $(n=8,219)$

Only clinical signs and CT Scan

4,180 (50.9)

PCR laboratory confirmed

4,039 (49.1)

$\operatorname{Sex}(n=6,308)$

Male

$2,822(44.7)$

Female

Comorbidity with COVID-19 ( $n=1,532)$

Hypertension

593 (38.7)

Diabetes

294 (19.2)

Respiratory system disease

$219(14.3)$

Cardiovascular and cerebrovascular diseases

$188(12.3)$

Cancer

Disease of immune system

59 (3.9)

Hepatitis

54 (3.5)

Liver disease

$33(2.1)$

Kidney disease

$32(2.1)$

the eye cells. ${ }^{[8]}$ Transmission of SARS-CoV-2 by tear is not unlikely, ${ }^{[53]}$ and the eye can be a way for entering the infection droplets to the body. ${ }^{[54]}$ Therefore, protecting eyes is essential for people, especially for healthcare providers to protect themselves against SARS-CoV-2.

The most important ocular manifestations in COVID-19 patients were dry eye or foreign body sensation, redness, tearing, itching, eye pain, and discharge. The mechanism of dry eye or foreign body sensation is unclear in COVID19 patients and may not be directly associated with SARS-CoV-2. Indeed, the occurrence of dry eye during the COVID-19 epidemic could be due to wearing face masks and directing the expiratory air current toward eyes, especially when masks are loose against the face and nose. The stream of air against ocular surface causes accelerated evaporation of the tear and may create dry eye symptoms. In persons with preexisting dry eye or poor-quality tear film, the symptoms can be more common and prominent. Limitation of access to lubricating agents in fear of contamination of hands and drug containers also deteriorates dry eye manifestations. ${ }^{[55,56]}$ Furthermore, since the beginning of the pandemic, people spend more time looking at screens that may exacerbate dry eye sensation. ${ }^{[57,58]}$ While screen watching, the rate and intensity of blinks is significantly diminished, exacerbating the dry eye symptoms. Loss of follow-up visits and reduced seeking care in patients with previous dry eye condition could be other factors that may have contributed to increased dry eye symptoms during the pandemic. ${ }^{[55,56]}$

Conjunctivitis was the most common eye disease in patients. Conjunctivitis could be developed by certain viruses (e.g., Haemophilus influenzae and Herpes simplex), bacteria (e.g., Staphylococcal species, Streptococcus pneumoniae, and Neisseria gonorrhoeae), and allergies (e.g., pollen and animal dander). ${ }^{[59]}$ Conjunctivitis could also be developed by coronavirus and SARS-CoV-2. ${ }^{[60,61]}$ In a study in Iran among 142 COVID-19 patients, the most prevalent ocular finding was conjunctival hyperemia (44 persons; 31\%); however, the most prevalent ocular manifestation among ICU-admitted patients was chemosis (17 out of 28 admitted to ICU; $60.7 \%$ ), and $50.0 \%$ of the patients admitted to ICU (14 of the 28) showed conjunctival hyperemia. ${ }^{[23]}$ Scalinci et al in a study among five Italian COVID-19 patients reported that conjunctivitis remained through the course of the disease among COVID-19 patients. ${ }^{[38]}$ Hong et $a l$ in a study in China showed that some 
Table 2. Symptoms and diseases of ocular in COVID-19 infection included in the reviewed studies $(n=1,021)$

Characteristics

N (\%)

Symptom and sign $(\mathrm{n}=\mathbf{9 3 2})$

Dry eyes or foreign body sensation

138 (16.0)

Redness

114 (13.3)

Tearing

111 (12.8)

Itching

109 (12.6)

Eye pain

$83(9.6)$

Discharge

$76(8.8)$

Blurred vision or decreased vision

$71(8.2)$

Photophobia

$62(7.2)$

Chemosis

42 (4.9)

Irritation

21 (2.4)

Gritty feeling

14 (1.6)

Burning sensation

8 (0.9)

Lid edema

$8(0.9)$

Subconjunctival hemorrhage

$3(0.3)$

Pseudomembrane and hemorrhage

$2(0.2)$

Pseudodendrite

Subepithelial infiltrates

$1(0.1)$

Water secretion

$1(0.1)$

Disease $(\mathbf{n}=\mathbf{8 9})$

Conjunctivitis

Keratitis

Episcleritis

$2(2.2)$

Keratoconjunctivitis

$2(2.2)$

Pingueculitis

Hordeolum

$2(2.2)$

Posterior ischemic optic neuropathy

1 (1.1)

Table 3. Meta-regression analysis of the effect of the factors on the ocular manifestations of the COVID-19 patients

\begin{tabular}{lccc}
\hline Variables & & Multivariable meta-regression \\
\hline & Coefficient & P-value & $-0.07-0.11$ \\
\hline $\begin{array}{l}\text { Quality of the included papers (quality } \geq 4 \text { vs } \\
\text { quality }<4 \text { ) }\end{array}$ & 0.02 & 0.59 \\
$\begin{array}{l}\text { The mean age of the patients }(\leq 45 \text { years vs }>45 \\
\text { years }\end{array}$ & -0.11 & 0.29 & $-0.35-0.13$ \\
$\begin{array}{l}\text { Clinical examination (standard ophthalmic exam vs } \\
\text { non-standard ophthalmic exam }\end{array}$ & 0.12 & 0.33 \\
$\begin{array}{l}\text { Diagnostic method (PCR vs CT Scan and clinical } \\
\text { signs) }\end{array}$ & -0.22 & 0.09 \\
$\begin{array}{l}\text { The recruited sample size (sample size }>500 \text { vs } \\
\text { sample size } \leq 500)\end{array}$ & -0.22 & 0.13 & $-0.17-0.42$ \\
\hline
\end{tabular}

conf., confidence 
patients reported conjunctivitis after admission for treatment of COVID-19. ${ }^{[19]}$ Chen et al in a crosssectional study in Wuhan China reported that some patients had conjunctivitis as their first symptom and others reported conjunctivitis after the clinical symptom of COVID-19 had begun. ${ }^{[21]}$ In a study in Canada, an association between conjunctivitis with corneal subepithelial infiltrations, corneal epithelial defects, development of tender preauricular lymphadenopathy, and conjunctival follicular reaction was observed among COVID-

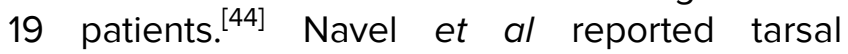
hemorrhage mucous filaments and tarsal pseudomembranous in one COVID-19 patient. They observed the eyelids were irritated by numerous sticky secretions accumulating around the eyelashes, and described mucous filaments, tarsal pseudomembranous, and superficial punctuate keratitis. ${ }^{[39]}$

Assessing and observing the symptoms and ocular manifestations of COVID-19 patients could improve clinicians' diagnosis of the disease. During the ongoing pandemic, ophthalmologists should consider COVID-19 as a potential diagnosis when observing ocular manifestations and conjunctivitis, especially with other manifestations of COVID19-like respiratory signs or fever. ${ }^{[60]}$ Incidence of ocular symptoms may happen a few hours or days before the onset of COVID-19 systemic signs such as fever and cough. ${ }^{[18,19,36]}$

Ophthalmologists are at a high risk for SARSCoV-2 given their close contact with patients. Although the transmission of SARS-CoV-2 via tear is not unlikely ${ }^{[53]}$ and the mechanism is uncertain, ${ }^{[8,62]}$ there exists a risk of transmission, ${ }^{[54]}$ and ophthalmologists and other healthcare providers should adhere to recommendations about wearing eye protective gears in addition to face masks and other protective devises during clinical examinations. ${ }^{[63]}$ This is particularly important when it comes to interactions with asymptomatic COVID-19 patients. ${ }^{[1]}$

We acknowledge the limitations of our study. First, ocular manifestations were measured by an ophthalmologist in some studies and through patient self-reports in others. Second, given the significant variations between the studies, we could not merge the results of different study designs. Third, most studies had a low sample size, and the quality of the included studies was low, and most were case reports and cross-sectional studies. Lastly, most COVID-19 patients are asymptomatic, but all patients enrolled in studies were symptomatic which could overestimate the infection's manifestations.

\section{SUMMARY}

Attention to ocular manifestations in combination with other COVID-19 manifestations could help improve COVID-19 diagnosis. The main ocular manifestations were dry eye, tearing, itching, redness, eye pain, and foreign body sensation. It is recommended that healthcare providers especially ophthalmologists who are in close contacts with patients wear eye protective goggles in addition to other recommended protective equipment.

\section{Financial Support and Sponsorship}

Nil.

\section{Conflicts of Interest}

There are no conflicts of interest.

\section{REFERENCES}

1. Veritti D, Sarao V, Bandello F, Lanzetta P. Infection control measures in ophthalmology during the COVID-19 outbreak: a narrative review from an early experience in Italy. Eur J Ophthalmol 2020;30:621-628.

2. Khalili M, Karamouzian M, Nasiri N, Javadi S, Mirzazadeh A, Sharifi H. Epidemiological characteristics of COVID-19: a systematic review and meta-analysis. Epidemiol Infect 2020;148:e130.

3. Worldometer. COVID-19 coronavirus pandemic [Internet]. Worldometer; 2020. Available from: https://www.worldometers.info/coronavirus/

4. Jin X, Lian JS, Hu JH, Gao J, Zheng L, Zhang YM, et al. Epidemiological, clinical and virological characteristics of 74 cases of coronavirus-infected disease 2019 (COVID-19) with gastrointestinal symptoms. Gut 2020;69:1002-1009.

5. Han C, Duan C, Zhang S, Spiegel B, Shi H, Wang W, et al. Digestive symptoms in COVID-19 patients with mild disease severity: clinical presentation, stool viral RNA testing, and outcomes. Am J Gastroenterol 2020;115:916923.

6. Renu K, Prasanna PL, Valsala Gopalakrishnan A. Coronaviruses pathogenesis, comorbidities and multiorgan damage - a review. Life Sci 2020;255:117839.

7. Seah I, Agrawal R. Can the Coronavirus Disease 2019 (COVID-19) affect the eyes? A review of Coronaviruses and ocular implications in humans and animals. Ocul Immunol Inflamm 2020;28:391-395.

8. Ho D, Low R, Tong L, Gupta V, Veeraraghavan A, Agrawal R. COVID-19 and the ocular surface: a review of transmission and manifestations. Ocul Immunol Inflamm 2020;28:726-734. 
9. Mahayana IT, Angsana NC, Kamila A, Fatiha NN, Sunjaya DZ, Andajana W, et al. Literature review of conjunctivitis, conjunctival swab and chloroquine effect in the eyes: a current updates on COVID-19 and ophthalmology. J Med Sci 2020;52:21-28.

10. Moher D, Liberati A, Tetzlaff J, Altman DG, Group P. Preferred reporting items for systematic reviews and meta-analyses: the PRISMA statement. PLOS Med 2009;6:e1000097.

11. Joanna Briggs Institute. The Joanna Briggs Institute Critical Appraisal tools for use in JBI systematic reviews checklist for prevalence studies [Internet]. Joanna Briggs Institute; 2017. Available from: http://joannabriggs.org/research/critical-appraisaltools.html

12. Zhang X, Chen X, Chen L, Deng C, Zou X, Liu W, et al. The evidence of SARS-CoV-2 infection on ocular surface. Ocul Surf 2020;18:360-362.

13. Xia J, Tong J, Liu M, Shen Y, Guo D. Evaluation of coronavirus in tears and conjunctival secretions of patients with SARS-CoV-2 infection. J Med Virol 2020;92:589594.

14. Wu P, Duan F, Luo C, Liu Q, Qu X, Liang L, et al. Characteristics of ocular findings of patients with Coronavirus Disease 2019 (COVID-19) in Hubei Province, China. JAMA Ophthalmol 2020;138:575-578.

15. Valente $P$, larossi G, Federici M, Petroni S, Palma $\mathrm{P}$, Cotugno $\mathrm{N}$, et al. Ocular manifestations and viral shedding in tears of pediatric patients with coronavirus disease 2019: a preliminary report. J AAPOS 2020:S10918531(20)30115-4.

16. Tostmann A, Bradley J, Bousema T, Yiek WK, Holwerda M, Bleeker-Rovers $C$, et al. Strong associations and moderate predictive value of early symptoms for SARS-CoV-2 test positivity among healthcare workers, the Netherlands, March 2020. Euro Surveill 2020;25:2000508.

17. Kumar K, Prakash AA, Gangasagara SB, Rathod SBL, Ravi $\mathrm{K}$, Rangaiah A, et al. Presence of viral RNA of SARS-CoV2 in conjunctival swab specimens of COVID-19 patients. Indian J Ophthalmol 2020;68:1015-1017.

18. Karimi S, Arabi A, Shahraki T, Safi S. Detection of severe acute respiratory syndrome Coronavirus-2 in the tears of patients with Coronavirus disease 2019. Eye 2020;34:1220-1223.

19. Hong N, Yu W, Xia J, Shen Y, Yap M, Han W. Evaluation of ocular symptoms and tropism of SARS-CoV2 in patients confirmed with COVID-19. Acta Ophthalmol 2020;26:10.1111/aos.14445.

20. Güemes-Villahoz N, Burgos-Blasco B, Arribi-Vilela A, Arriola-Villalobos P, Rico-Luna CM, Cuiña-Sardiña R, et al. Detecting SARS-CoV-2 RNA in conjunctival secretions: is it a valuable diagnostic method of COVID-19? J Med Virol 2020:10.1002/jmv.26219.

21. Chen L, Deng C, Chen X, Zhang X, Chen B, Yu H, et al. Ocular manifestations and clinical characteristics of 535 cases of COVID-19 in Wuhan, China: a cross-sectional study. Acta Ophthalmol 2020;10.1111/aos.14472.

22. Bostanci Ceran B, Ozates S. Ocular manifestations of coronavirus disease 2019. Graefes Arch Clin Exp Ophthalmol 2020:258:1959-1963.

23. Abrishami M, Tohidinezhad F, Daneshvar R, Omidtabrizi A, Amini M, Sedaghat A, et al. Ocular manifestations of hospitalized patients with COVID-19 in Northeast of Iran. Ocul Immunol Inflamm 2020:28:739-744.

24. Lapostolle F, Schneider E, Vianu I, Dollet G, Roche B, Berdah J, et al. Clinical features of 1487 COVID-19 patients with outpatient management in the Greater Paris: the COVID-call study. Intern Emerg Med 2020:15:813-817.

25. Ye $\mathrm{Y}$, Song $\mathrm{Y}$, Yan $\mathrm{M}, \mathrm{Hu} \mathrm{C}$, Chen $\mathrm{X}, \mathrm{Yu} \mathrm{J}$, et al. Novel coronavirus pneumonia combined with conjunctivitis: three cases report. Zhonghua Shiyan Yanke Zazhi/Chinese J Exp Ophthalmol 2020;38:242244.

26. Seah IYJ, Anderson DE, Kang AEZ, Wang L, Rao P, Young BE, et al. Assessing viral shedding and infectivity of tears in Coronavirus Disease 2019 (COVID-19) patients. Ophthalmology 2020;127:977-979.

27. Deng $C$, Yang $Y$, Chen $H$, Chen W, Chen Z, Ma K, et al. Ocular dectection of SARS-CoV-2 in 114 cases of COVID-19 pneumonia in Wuhan, China: an observational study [Internet]. SSRN; 2020. Available from: http://www. ssrn.com/abstract $=3543587$

28. Xu L, Zhang $X$, Song $\mathrm{W}$, Sun $\mathrm{B}, \mathrm{Mu} J$, Wang $\mathrm{B}$, et al. Conjunctival polymerase chain reaction-tests of 2019 novel coronavirus in patients in Shenyang, China [Internet]. SSRN; 2020. Available from: https://www.ssrn. com/abstract $=3543592$

29. Guan W-j, Ni Z-y, Hu Y, Liang W-h, Ou C-q, He J-x, et al. Clinical characteristics of coronavirus disease 2019 in China. N Engl J Med 2020;382:1708-1720.

30. Zhou $Y$, Duan $C$, Zeng $Y$, Tong $Y$, Nie $Y$, Yang $Y$, et al. Ocular findings and proportion with conjunctival SARS-COV-2 in COVID-19 patients. Ophthalmology 2020;127:982-983.

31. Lechien JR, Chiesa-Estomba CM, Place S, Van Laethem Y, Cabaraux P, Mat Q, et al. Clinical and epidemiological characteristics of 1420 European patients with mildto-moderate coronavirus disease 2019. J Intern Med 2020;288:335-344.

32. Pardhan S, Vaughan M, Zhang J, Smith L, Chichger $H$. Type and frequency of ocular and other known symptoms experienced by people who self diagnosed as suffering from COVID-19 in the UK. medRxiv 2020.

33. Liang $\mathrm{L}, \mathrm{Wu} \mathrm{P}$. There may be virus in conjunctival secretion of patients with COVID-19. Acta Ophthalmol 2020;98:223.

34. Sindhuja K, Lomi N, Asif MI, Tandon R. Clinical profile and prevalence of conjunctivitis in mild COVID-19 patients in a tertiary care COVID-19 hospital: a retrospective crosssectional study. Indian J Ophthalmol 2020;68:1546-1550.

35. Wu F, Zhou Y, Wang Z, Xie M, Shi Z, Tang Z, et al. Clinical characteristics of COVID-19 infection in chronic obstructive pulmonary disease: a multicenter, retrospective, observational study. J Thorac Dis 2020;12:1811-1823.

36. Huang L, Zhang $X$, Zhang $X$, Wei Z, Zhang L, Xu J, et al. Rapid asymptomatic transmission of COVID-19 during the incubation period demonstrating strong infectivity in a cluster of youngsters aged 16-23 years outside Wuhan and characteristics of young patients with COVID-19: a prospective contact-tracing study. J Infect 2020;80:e1e13.

37. Selvaraj V, Sacchetti D, Finn A, Dapaah-Afriyie K. Acute vision loss in a patient with COVID-19. $R$ I Med $J$ 2020;103:37-38. 
38. Scalinci SZ, Trovato Battagliola E. Conjunctivitis can be the only presenting sign and symptom of COVID-19. IDCases 2020;20:e00774.

39. Navel V, Chiambaretta F, Dutheil F. Haemorrhagic conjunctivitis with pseudomembranous related to SARSCoV-2. Am J Ophthalmol Case Rep 2020;19:100735.

40. Li X, Wang M, Dai J, Wang W, Yang Y, Jin W. Novel coronavirus disease with conjunctivitis and conjunctivitis as first symptom: two cases report. [Zhonghua Shiyan Yanke Zazhi] Chinese J Exp Ophthalmol 2020;38:318321.

41. Lan $Q Q$, Zeng SM, Liao X, Xu F, Qi H, Li M. [Screening for novel coronavirus related conjunctivitis among the patients with corona virus disease-19]. [Zhonghua yan ke za zhi] Chinese J Ophthalmol 2020;56:E009.

42. Daruich A, Martin D, Bremond-Gignac D. Ocular manifestation as first sign of Coronavirus Disease 2019 (COVID-19): interest of telemedicine during the pandemic context. J Fr Ophtalmol 2020;43:389-391.

43. Chen L, Liu M, Zhang Z, Qiao K, Huang T, Chen M, et al. Ocular manifestations of a hospitalised patient with confirmed 2019 novel coronavirus disease. $\mathrm{Br} \mathrm{J}$ Ophthalmol 2020;104:748-751.

44. Cheema M, Aghazadeh H, Nazarali S, Ting A, Hodges $J$, McFarlane A, et al. Keratoconjunctivitis as the initial medical presentation of the novel coronavirus disease 2019 (COVID-19). Can J Ophthalmol 2020;55:e125-e129.

45. Chavis A, Bakken H, Ellenby M, Hasan R. Coronavirus Disease-2019 and telehealth: prevention of exposure in a medically complex patient with a mild presentation. $J$ Adolesc Health 2020;67:456-458.

46. Ozturker ZK. Conjunctivitis as sole symptom of COVID19: a case report and review of literature [published online ahead of print, 2020, Jul 24]. Eur J Ophthalmol 2020;1120672120946287.

47. Nayak B, Poddar C, Panigrahi MK, Tripathy S, Mishra B. Late manifestation of follicular conjunctivitis in ventilated patient following COVID-19 positive severe pneumonia. Indian J Ophthalmol 2020;68:1675-1677.

48. Guo D, Xia J, Wang Y, Zhang X, Shen Y, Tong JP. Relapsing viral keratoconjunctivitis in COVID-19: a case report. Virol J 2020;17:97.

49. Salducci M, La Torre G. COVID-19 emergency in the cruise's ship: a case report of conjunctivitis. Clin Ter 2020;171:e189-e91.

50. Lai C-C, Ko W-C, Lee P-I, Jean S-S, Hsueh P-R. Extrarespiratory manifestations of COVID-19. Int J Antimicrob Agents 2020;56:106024.
51. Vabret A, Mourez T, Dina J, van der Hoek L, Gouarin S, Petitjean J, et al. Human coronavirus NL63, France. Emerg Infect Dis 2005;11:1225-1229.

52. Ulhaq ZS, Soraya GV. The prevalence of ophthalmic manifestations in COVID-19 and the diagnostic value of ocular tissue/fluid. Graefes Arch Clin Exp Ophthalmol 2020;258:1351-1352.

53. Abobaker A, Raba AA, Alzwi A. Extrapulmonary and atypical clinical presentations of COVID-19. J Med Virol 2020;10.1002/jmv.26157.

54. Dockery DM, Rowe SG, Murphy MA, Krzystolik MG. The ocular manifestations and transmission of COVID19: recommendations for prevention. J Emerg Med 2020;59:137-140.

55. Giannaccare G, Vaccaro S, Mancini A, Scorcia V. Dry eye in the COVID-19 era: how the measures for controlling pandemic might harm ocular surface. Graefes Arch Clin Exp Ophthalmol 2020;258:2567-2568.

56. Patel S, Henderson R, Bradley L, Galloway B, Hunter L. Effect of visual display unit use on blink rate and tear stability. Optom Vis Sci 1991;68:888-892.

57. Marinova E, Dabov D, Zdravkov Y. Ophthalmic complaints in face-mask wearing: prevalence, treatment, and prevention with a potential protective effect against SARSCoV-2. Biotechnol Biotechnol Equip 2020;34:1323-1336.

58. Moshirfar M, West WB, Marx DP. Face mask-associated ocular irritation and dryness. Ophthalmol Ther 2020;9:397-400.

59. Azari AA, Barney NP. Conjunctivitis: a systematic review of diagnosis and treatment. JAMA 2013;310:1721-1729.

60. Amesty MA, Alió del Barrio JL, Alió JL. COVID-19 disease and ophthalmology: an update. Ophthalmol Ther 2020;9:1-12.

61. Guo D, Xia J, Shen Y, Tong J. SARS-CoV-2 may be related to conjunctivitis but not necessarily spread through the conjunctiva SARS-CoV-2 and conjunctiva. J Med Virol 2020;10.1002/jmv.25856.

62. Loon SC, Teoh SC, Oon LL, Se-Thoe SY, Ling AE, Leo YS, et al. The severe acute respiratory syndrome coronavirus in tears. Br J Ophthalmol 2004;88:861-863.

63. Chen X, Yu H, Mei T, Chen B, Chen L, Li S, et al. SARSCoV-2 on the ocular surface: is it truly a novel transmission route? Br J Ophthalmol 2020;bjophthalmol-2020-316263. 